\title{
Host range and symptomatology of Pepino mosaic virus strains occurring in Europe
}

\author{
Dag-Ragnar Blystad • René van der Vlugt • Ana Alfaro-Fernández • \\ María del Carmen Córdoba • Gábor Bese • Dimitrinka Hristova • \\ Henryk Pospieszny • Nataša Mehle • Maja Ravnikar • Laura Tomassoli • \\ Christina Varveri • Steen Lykke Nielsen
}

Accepted: 15 April 2015 / Published online: 24 April 2015

(C) The Author(s) 2015. This article is published with open access at Springerlink.com

\begin{abstract}
Pepino mosaic virus (PepMV) has caused great concern in the greenhouse tomato industry after it was found causing a new disease in tomato in 1999. The objective of this paper is to investigate alternative hosts and compare important biological characteristics of the three PepMV strains occurring in Europe when tested under different environmental conditions. To this end we compared the infectivity and symptom development of three, well characterized isolates belonging to three different PepMV strains, EU-tom, Ch2 and US1, by inoculating them on tomato, possible alternative host plants in the family Solanaceae and selected test plants. The inoculation experiments were done in 10 countries
\end{abstract}

\section{D.-R. Blystad ( $\triangle)$}

Bioforsk - Norwegian Institute for Agricultural and

Environmental Research, Høgskoleveien 7, N-1430 Aas,

Norway

e-mail: dag-ragnar.blystad@bioforsk.no

R. van der Vlugt

Wageningen UR, Plant Research International, P.O. Box 16, NL-6700 AA Wageningen, The Netherlands

A. Alfaro-Fernández $\cdot$ M. del Carmen Córdoba Instituto Agrofestal Del Mediterráneo, Universidad Politécnica de Valencia Camino de Vera s/n, 46022 Valencia, Spain

G. Bese

Csongrád Megyei Mezőgazdasági Szakigazgatási Hivatal Növény- és Talajvédelmi Igazgatóság Rárósi út 110, PO Box 99, 6801 Hódmezovásárhely, Hungary

D. Hristova

Plant Protection Institute (PPI), 2230 Kostinbrod, Bulgaria from south to north in Europe. The importance of alternative hosts among the solanaceous crops and the usefulness of test plants in the biological characterization of PepMV isolates are discussed. Our data for the three strains tested at 10 different European locations with both international and local cultivars showed that eggplant is an alternative host of PepMV. Sweet pepper is not an important host of PepMV, but potato can be infected when the right isolate is matched with a specific cultivar. Nicotiana occidentalis $37 \mathrm{~B}$ is a useful indicator plant for PepMV studies, since it reacts with a different symptomatology to each one of the PepMV strains.

\section{H. Pospieszny \\ Institute for Plant Protection (IOR), W. Wegorka 20, \\ 60-318 Poznan, Poland}

N. Mehle $\cdot$ M. Ravnikar

National Institute of Biology, Večna pot 111,

SI-1000 Ljubljana, Slovenia

\section{Tomassoli}

Consiglio per la Ricerca e sperimentazione in Agricoltura (Centro di ricerca per la patologia vegetale), I-00156 Rome, Italy

C. Varveri

Benaki Phytopathological Institute, 8 St. Delta Street, 14561 Kifissia, Greece

S. L. Nielsen

Department of Agroecology, Aarhus University, Forsøgsvej 1, DK-4200 Slagelse, Denmark 
Keywords Pepino mosaic virus · Potexvirus · Strains · Host plants · Test plants

\section{Introduction}

Pepino mosaic virus (PepMV) was first reported in Europe in the late 1990s (Wright and Mumford 1999; van der Vlugt et al. 2000), and has been regarded as a threat to tomato (Solanum lycopersicum) crops in several European countries ever since. PepMV was first described infecting pepino ( $S$. muricatum) in Peru (Jones et al. 1980), and as such was neither regarded as a serious pathogen nor as an emerging one for other crop species. This scene, however, changed in 1999 when PepMV was detected infecting tomato crops in the main tomato growing areas in the Netherlands and Great Britain (Wright and Mumford 1999; van der Vlugt et al. 2000). PepMV was later detected in most European countries. The pest risk analysis (PRA) issued in 2010 (Werkman and Sansford 2010) which resulted from the EU FP6 funded PEPEIRA project, lists the occurrence of PepMV in tomato crops in several European countries: Austria, Belgium, Canary Islands, Cyprus, the Czech Republic (declared eradicated), Denmark, France, Germany, Hungary, Ireland, Italy, the Netherlands, Norway (eradicated), Poland, Romania, Slovak Republic, Spain, Sweden, Ukraine and the United Kingdom. Outside Europe PepMV has been found affecting tomato crops in USA, Canada, Chile, Ecuador, Guatemala, Peru, Morocco and China. Recently, PepMV has also been reported from Mexico (Ling and Zhang 2011), Greece (Efthimiou et al. 2011) and South Africa (Charmichael et al. 2011).

As tomato is one of the most valuable crops in Europe, it is important to know the effect of PepMV on the tomato crop and also to know if other solanaceous crops could be affected by this virus or may play a role in its epidemiology. The presence of three PepMV strains in Europe may complicate this picture as they may differ in symptomatology or aggressiveness in their effect on tomato and have possible different alternative hosts.

PepMV belongs to the genus Potexvirus, family Alphaflexiviridae (King et al. 2012) with filamentous particles about $500 \mathrm{~nm}$ long and a monopartite, positivestrand RNA genome containing five open reading frames as typically reported for potexviruses (VerchotLubicz et al. 2007). As for most potexviruses PepMV mainly spreads mechanically from plant to plant without the involvement of an obvious vector (King et al. 2012). There is evidence that bumble bees (Shipp et al. 2008), the soil-borne fungus Olpidium virulentus (AlfaroFernández et al. 2009) and whiteflies (Noël et al. 2014) can function as vectors for PepMV. Seed transmission is likely to play a role in long distance spread (Córdoba-Sellés et al. 2007; Hanssen et al. 2010), and water was confirmed to be the source of PepMV infection (Schwarz et al. 2010; Mehle et al. 2014).

As PepMV was found in several locations and countries, a number of different strains were reported (Van der Vlugt and Stijger 2008). Currently five main strains of PepMV are recognized (Hanssen et al. 2009; van der Vlugt and Stijger 2008; van der Vlugt 2009; MorenoPérez et al. 2014): 1) the Peruvian (PE) strain, originally found on pepino (S. muricatum) and wild Solanum spp., 2) the EU-tomato (EU-tom) strain, 3) the US1/Ch1 strain, 4) the Chile-2 (Ch2) strain, and 5) the PES strain of PepMV recently found and described in wild tomato populations in Peru.

Determining the host range of PepMV has been an essential part of the work carried out by several research groups. PepMV causes a variety of symptoms in tomato (Van der Vlugt et al. 2000; Hanssen et al. 2009). PepMV has also been found to infect several other solanaceous crops and test plants like Datura stramonium, Nicotiana benthamiana, Physalis floridana, S. melongena (eggplant) and $S$. tuberosum (potato). PepMV is known to infect a relatively broad host range of plants representing different families, including both cultivated and wild hosts. Most host species are in the family Solanaceae, but several solanaceous hosts do not support systemic infection (Jones et al. 1980; Martin and Mousserion 2002; Salomone and Roggero 2002; Verhoeven et al. 2003; Jordá et al. 2001; Córdoba et al. 2004).

Although several authors distinguished strains on the basis of their host range and symptoms in test plants (Jones et al. 1980; Martin and Mousserion 2002; Pagan et al. 2006; Salomone and Roggero 2002; Verhoeven et al. 2003), there is still a lack of comparable data on alternative hosts within the solanaceous family and also on the symptoms of different strains in test plants under different climatic conditions.

Most individual studies report on one or two isolates studied on one location. The objective of the present study was to determine the most important biological characteristics of three well-defined PepMV strains 
present in tomato in Europe, and to determine the possible risks of PepMV strains to tomato and other solanaceous crops. By inoculating isolates belonging to the main strains found in Europe on solanaceous crops and indicator plants in ten different locations throughout Europe, a comprehensive data set is herein presented.

\section{Materials and methods}

Isolates, propagation and inoculation procedure

Isolates from three PepMV strains were included in the trials: 1) isolate PD99901066 belonging to the EU-tom strain (Van der Vlugt et al. 2002), 2) isolate PCH06/104 belonging to the $\mathrm{Ch} 2$ strain (Hanssen et al. 2008), and 3) isolate US1-PRI (US1 strain). The isolates were distributed to different laboratories as freeze dried leaf material of PepMV infected $N$. benthamiana. Virus isolates were inoculated locally by standard procedure (Jeffries 1998) and propagated in $N$. benthamiana before they were used for further inoculation experiments. The plants were inoculated at the stage of 3-4 full-grown leaves. Five plants of each cultivar under investigation were inoculated with the isolates used, and as a control one plant was inoculated with water or buffer. The inoculated plants were observed regularly for local and systemic symptom development in a period of 4-5 weeks post inoculation. For description of symptoms a common vocabulary was used by all partners. The trials were carried out in each partner's glass- or screenhouse facility under local conditions and the plants were nursed according to local practises.

\section{Locations}

To study virus symptoms under different climatic conditions and on different varieties of selected crop plants, the work was done at 10 laboratories in 10 countries throughout Europe: Bulgaria (BG), Denmark (DK), Greece (EL), Hungary (HU), the Netherlands (NL), Italy (IT), Norway (NO), Poland (PL), Slovenia (SI) and Spain (ES).

Solanaceous crops, reference cultivars and locally grown cultivars

The following economically important solanaceous crops were tested: C. annuиm (sweet pepper),
S. lycopersicum (tomato), S. melongena (eggplant) and S. tuberosum (potato).

Not all plant species were tested by all partners. The main principle was that all partners testing a specific plant species had to include a common reference cultivar of such species and supplement the study with locally grown cultivars after their own choice. Seeds for the selected common reference cultivars and the Nicotiana species were provided from the same seed lots and distributed to the partners. The reference cultivars were C. annuиm 'Bell Boy', S. lycopersicum 'Moneymaker' and $S$. melongena 'Black Beauty'. In potato the reference cultivar Bintje was provided as virus-free tested in vitro plants from the Danish Potato Nuclear Stock Collection except Norway using virus-free 'Bintje' from its own national tissue culture collection. The locally chosen potato cultivars were established as stem cuttings or in vitro plants and tested for absence of common potato viruses by DAS-ELISA before inoculation.

A summary of the total results over all countries of infection rates of three PepMV isolates in the five crops, as determined by ELISA and development of systemic symptoms, is shown in Table 6 to facilitate an overview of the most important results in relation to the discussion.

Indicator plants

A selection of indicator plant species were included to investigate the possibility to differentiate between the three viral strains based on symptom development. These indicators comprised $N$. benthamiana, N. glutinosa, N. occidentalis 37B, N. rustica, $N$. tabacum cv. Xanthi and Chenopodium quinoa. The use of test plants is important for virus isolation, propagation and for differentiation of isolates. Symptoms may vary according to growth conditions and genetic variability of the test plants. For this latter reason seeds of $N$. occidentalis 37B from the same source (PRI, the Netherlands) were distributed to all participants in this study. For the other test plants the seeds from the local institutes' seed banks were used.

\section{ELISA}

The inoculated plants were checked for systemic infection by DAS-ELISA and in several cases back inoculated to suitable test plants to confirm infection. ELISA was performed using a commercially available ELISA 
assay according to the suppliers' instructions (Prime Diagnostics, Wageningen, The Netherlands). Samples were rated positive if the mean optical density at $405 \mathrm{~nm}$ (OD) of the sample exceeded two times the mean of two wells containing extract from healthy plants of the same species/cultivar (Samson et al. 1993).

\section{Results}

\section{Eggplant (S. melongena)}

Five partners tested symptom development in S. melongena with the reference cv. Black Beauty being tested by all partners (Table 1). In four of the partner laboratories no local symptoms developed in this cultivar with the exception of the tests in Bulgaria where local necrotic lesions were recorded. Only in inoculation tests carried out in Bulgaria did US1 develop systemic symptoms in the form of necrotic lesions in the cv.

Table 1 Symptom development in different European countries of three PepMV isolates in Solanum melongena cv. Black Beauty and results of ELISA tests on leaves and roots of inoculated plants and on leaves of back inoculated plants

\begin{tabular}{|c|c|c|c|c|c|c|}
\hline \multirow[t]{2}{*}{$\begin{array}{l}\text { PepMV } \\
\text { isolate }\end{array}$} & \multirow[t]{2}{*}{ Country } & \multicolumn{2}{|c|}{ Symptoms } & \multicolumn{2}{|c|}{$\begin{array}{l}\text { DAS ELIS } \\
\text { Apos/neg }\end{array}$} & \multirow{2}{*}{$\begin{array}{l}\text { Back } \\
\text { inoculated } \\
\text { leaves }\end{array}$} \\
\hline & & local & systemic & leaves & roots & \\
\hline \multirow{5}{*}{$\begin{array}{c}\text { EU-tom } \\
1066\end{array}$} & BG & $\mathrm{nl}$ & $\mathrm{m}$ & pos & pos & pos \\
\hline & ES & ns & $\mathrm{ns}$ & pos & pos & pos \\
\hline & IT & ns & $\mathrm{m}, \mathrm{lb}, \mathrm{gr}$ & pos & pos & $\mathrm{nt}$ \\
\hline & PL & $\mathrm{ns}$ & $\mathrm{ns}$ & pos & $\mathrm{nt}$ & pos \\
\hline & SI & ns & $\mathrm{ns}$ & pos & $\mathrm{nt}$ & pos \\
\hline \multirow{5}{*}{$\begin{array}{c}\mathrm{Ch} 2 \mathrm{PCH} \\
06 / 104\end{array}$} & BG & $\mathrm{nl}$ & $\mathrm{nl}$ & pos & pos & pos \\
\hline & ES & $\mathrm{ns}$ & lc, ys, m & pos & $\mathrm{nt}$ & pos \\
\hline & IT & ns & $\mathrm{m}$ & pos & pos & pos \\
\hline & PL & $\mathrm{ns}$ & $\mathrm{ns}$ & pos & $\mathrm{nt}$ & pos \\
\hline & SI & ns & lc & pos & $\mathrm{nt}$ & pos \\
\hline \multirow[t]{5}{*}{ US1-PRI } & BG & $\mathrm{nl}$ & $\mathrm{nl}$ & pos & pos & pos \\
\hline & ES & $\mathrm{ns}$ & $\mathrm{ns}$ & pos & pos & pos \\
\hline & IT & $\mathrm{ns}$ & $\mathrm{ns}$ & pos & pos & pos \\
\hline & PL & ns & $\mathrm{ns}$ & pos & $\mathrm{nt}$ & pos \\
\hline & SI & ns & $\mathrm{ns}$ & pos & $\mathrm{nt}$ & pos \\
\hline
\end{tabular}

$B G$ Bulgaria, ES Spain, IT Italy, PL Poland, SI Slovenia

$n t$ not tested, $g r$ growth reduction, $l b$ leaf bubbling, $l c$ leaf chlorosis, $m$ mosaic, $n l$ necrotic lesion, $n s$ no symptoms, $y s$ yellow spots
Black Beauty. The other two strains produced different forms of systemic symptoms in several countries with $\mathrm{Ch} 2$ inducing symptoms in most locations. ELISA tests of inoculated plants and back inoculations were all positive.

The results of the tests of the different local eggplant cultivars are shown in Table 2. For all three virus strains most cultivars showed no local symptoms, the same pattern as observed with 'Black Beauty'. Only under Bulgarian growth conditions all three strains caused necrotic lesions. The pattern of development of systemic symptoms was more complicated. In Spain infection with EU-tom did not result in any symptoms on the three cultivars tested and in Italy the same applied to 'Lunga de Napoli' while $\mathrm{Ch} 2$ induced symptoms in cultivars assayed in Spain and Italy. US1 did not infect local eggplant varieties in the inoculation trials in Spain. In general, infection with $\mathrm{Ch} 2$ resulted in the most severe and diverse symptoms, while EU-tom infections showed the mildest symptoms. ELISA tests of leaves showed that where no symptoms were recorded, the plants were nevertheless latently infected. Where tests of roots and back inoculations were included, these were all positive.

In conclusion (see Table 6), PepMV easily infects S. melongena systemically and in most cases induces systemic symptoms. It seldom develops local symptoms. Symptom expression depends on the virus strain, the plant genotype and the environmental conditions.

\section{Sweet pepper (Capsicum annuиm)}

Five partners carried out inoculation experiments with in total 16 cultivars of $C$. annuum, while the reference cv. Bell Boy was included by all partners. No symptoms were recorded in any of the cultivars except systemic necrotic lesions induced by US1 in cvs. Bell Boy, Bulgarski ratund and Sivrija, all in Bulgaria. ELISA tests of inoculated leaves of inoculated plants were negative except for all three virus strains in cvs. Bell Boy, Rubeiro and Superset in Norway, US1 in cvs. Bell Boy and Bularski ratund in Bulgaria and EU-tom in cv. Šorokšari in Slovenia. Where ELISA test of roots and back inoculation of inoculated leaves were included, all gave negative results.

In conclusion, generally no symptoms were observed except for the isolate US1 provoking necrotic lesions in 
Table 2 Symptom development in different European countries of three PepMV isolates in local cultivars of Solanum. melongena and results of ELISA tests on leaves and roots of inoculated plants

\begin{tabular}{|c|c|c|c|c|c|c|c|}
\hline \multirow[t]{2}{*}{ PepMV isolate } & \multirow[t]{2}{*}{ Country } & \multirow[t]{2}{*}{ Cultivar } & \multicolumn{2}{|c|}{ Symptoms } & \multicolumn{2}{|c|}{$\begin{array}{l}\text { DAS ELISA } \\
\text { pos/neg }\end{array}$} & \multirow{2}{*}{$\begin{array}{l}\text { Back } \\
\text { inoculated } \\
\text { leaves }\end{array}$} \\
\hline & & & local & systemic & leaves & roots & \\
\hline \multirow[t]{10}{*}{ EU-tom 1066} & BG & White & $\mathrm{nl}$ & $\mathrm{m}$ & pos & pos & pos \\
\hline & BG & 12 & $\mathrm{nl}$ & $\mathrm{m}$ & pos & pos & pos \\
\hline & ES & Romanesca & ns & ns & pos & pos & pos \\
\hline & ES & Almagro & ns & ns & pos & pos & pos \\
\hline & ES & Lunga de Napoli & $\mathrm{ns}$ & ns & pos & pos & pos \\
\hline & IT & Lunga de Napoli & ns & ns & pos & pos & $\mathrm{nt}$ \\
\hline & IT & Romanesca & ns & $\mathrm{m}, \mathrm{gr}$ & pos & pos & $\mathrm{nt}$ \\
\hline & PL & Violetta Lunga 3 & nt & ns & pos & nt & pos \\
\hline & SI & Lunga de Napoli & ns & lc & pos & nt & pos \\
\hline & SI & Romanesca & ns & lc & pos & $\mathrm{nt}$ & pos \\
\hline \multirow[t]{10}{*}{ Ch2 PCH06/104 } & BG & White & $\mathrm{nl}$ & $\mathrm{nl}$ & pos & pos & pos \\
\hline & BG & 12 & $\mathrm{nl}$ & $\mathrm{nl}$ & pos & pos & pos \\
\hline & ES & Romanesca & ns & lc, lb, ys & pos & $\mathrm{nt}$ & pos \\
\hline & ES & Almagro & ns & lc, m, ys, vn, lb & pos & $\mathrm{nt}$ & pos \\
\hline & ES & Lunga de Napoli & ns & $\mathrm{m}$ & pos & nt & pos \\
\hline & IT & Lunga de Napoli & $\mathrm{ns}$ & $\mathrm{m}, \mathrm{vb}$ & pos & pos & pos \\
\hline & IT & Romanesca & ns & $\mathrm{m}, \mathrm{vb}$ & pos & pos & pos \\
\hline & PL & Violetta Lunga 3 & $\mathrm{nt}$ & ns & pos & nt & pos \\
\hline & SI & Lunga de Napoli & $\mathrm{ns}$ & ns & pos & nt & pos \\
\hline & SI & Romanesca & $\mathrm{ns}$ & $\mathrm{lc}, \mathrm{m}$ & pos & $\mathrm{nt}$ & pos \\
\hline \multirow[t]{10}{*}{ US1-PRI } & BG & White & $\mathrm{nl}$ & $\mathrm{nl}$ & pos & pos & pos \\
\hline & BG & 12 & $\mathrm{nl}$ & $\mathrm{nl}, \mathrm{gr}$ & pos & pos & pos \\
\hline & ES & Romanesca & $\mathrm{ns}$ & ns & neg & neg & $\mathrm{nt}$ \\
\hline & ES & Almagro & ns & ns & neg & neg & nt \\
\hline & ES & Lunga de Napoli & ns & ns & neg & neg & $\mathrm{nt}$ \\
\hline & IT & Lunga de Napoli & $\mathrm{ns}$ & ns & pos & pos & pos \\
\hline & IT & Romanesca & $\mathrm{ns}$ & $\mathrm{m}$ & pos & pos & pos \\
\hline & PL & Violetta Lunga 3 & $\mathrm{nt}$ & $\mathrm{m}$ & pos & $\mathrm{nt}$ & pos \\
\hline & SI & Lunga de Napoli & ns & lc & pos & $\mathrm{nt}$ & pos \\
\hline & SI & Romanesca & ns & lc, $\ln$ & pos & $\mathrm{nt}$ & pos \\
\hline
\end{tabular}

$n t$ not tested, $g r$ growth reduction, $l b$ leaf bubbling, $l c$ leaf chlorosis, $l n$ leaf necrosis, $m$ mosaic, $n l$ necrotic lesion, $n s$ no symptoms, $v b$ vein banding, $v n$ veinal necrosis, ys yellow spots

3 out of 20 experiments. ELISA results showed a few cases of latent local infection.

As summarized in Table 6, C. annuum in general is not a systemic host for the three virus strains used in this study, and it is likely that C. annuum does not represent an important host in the epidemiology of PepMV. and on leaves of back inoculated plants $B G$ Bulgaria, ES Spain, $I T$ Italy, PL Poland, SI Slovenia 
Poland and cv. Caesar in the Netherlands. The reference cv. Bintje was included by three partners. In most cultivars none of the tested strains caused any symptoms. Local necrotic lesions were induced by EU-Tom in cvs. Concord, Juno, Riviera and Caesar, by $\mathrm{Ch} 2$ in cvs. Juno and Caesar and by US1 in cv. Caesar, while mild systemic mosaic was only induced by $\mathrm{Ch} 2$ in cv. Beate and mild systemic leaf chlorosis by all three strains in $\mathrm{cv}$. Caesar (Table 3). Despite the absence of local and systemic symptoms in most cultivars, ELISA tests of systemic leaves of the inoculated plants did show positive infections with eight, six and five cultivars for EUtom, Ch2 and US1, respectively. The standard cv. Bintje and cultivars that developed symptoms or infection are listed in Table 3. Interestingly for EU-tom, six out of six back-inoculations tested positive while for $\mathrm{Ch} 2$ two out of four and for US1 only one out of three back inoculations tested positive, clearly confirming the systemic infection of the different inoculated potato cultivars.

The cvs. Beate in Norway and Caesar in the Netherlands were the only cultivars that developed systemic symptoms in the inoculation experiments described above. The Norwegian partner also included another PepMV isolate: TomA2001-1 in the study (a Ch2 strain isolate, Van der Vlugt unpublished). The TomA2001-1 isolate gave systemic mosaic symptoms in five out of five plants of the cv. Beate, and the presence of PepMV in the systemically infected leaves was confirmed by ELISA. Harvested tubers from these plants were stored and planted 6 months later. In the resulting plants, the same mosaic symptoms were observed and, the secondary PepMV infection was confirmed by ELISA and electron microscopy.
Table 3 Symptom development in different European countries of three PepMV isolates in cultivars of Solanum tuberosum and results of ELISA tests on leaves and roots of inoculated plants and on leaves of back inoculated plants. This table shows data for the standard cv. Bintje and cultivars that developed symptoms or infection
$B G$ Bulgaria, $D K$ Denmark, $N O$

Norway, $P L$ Poland, $N L$

The Netherlands

$n t$ not tested, $g r$ growth reduction, $l b$ leaf bubbling, $l c$ leaf chlorosis, $l n$ leaf necrosis, $m$ mosaic, $n l$ necrotic lesion, $n s$ no symptoms, $v b$ vein banding, $v n$ veinal necrosis, ys yellow spots

\begin{tabular}{|c|c|c|c|c|c|c|c|}
\hline \multirow[t]{2}{*}{ PepMV isolate } & \multirow[t]{2}{*}{ Country } & \multirow[t]{2}{*}{ Cultivar } & \multicolumn{2}{|c|}{ Symptoms } & \multicolumn{2}{|c|}{$\begin{array}{l}\text { DAS ELISA } \\
\text { pos/neg }\end{array}$} & \multirow{2}{*}{$\begin{array}{l}\text { Back } \\
\text { inoculated } \\
\text { leaves }\end{array}$} \\
\hline & & & local & systemic & leaves & roots & \\
\hline \multirow[t]{10}{*}{ EU-tom 1066} & NO & Bintje & ns & ns & neg & $\mathrm{nt}$ & nt \\
\hline & NO & Beate & ns & ns & pos & $\mathrm{nt}$ & $\mathrm{nt}$ \\
\hline & $\mathrm{NO}$ & Juno & $\mathrm{nl}$ & ns & neg & nt & $\mathrm{nt}$ \\
\hline & DK & Mette & ns & ns & pos & neg & pos \\
\hline & $\mathrm{BG}$ & Riviera & $\mathrm{nl}$ & ns & pos & neg & pos \\
\hline & BG & Concord & $\mathrm{nl}$ & ns & pos & neg & pos \\
\hline & PL & Natascha & ns & ns & pos & $\mathrm{nt}$ & Pos \\
\hline & PL & Jelly & ns & ns & pos & nt & Pos \\
\hline & PL & Dali & ns & ns & pos & $\mathrm{nt}$ & pos \\
\hline & $\mathrm{NL}$ & Caesar & $\mathrm{nl}$ & lc & pos & $\mathrm{nt}$ & $\mathrm{nt}$ \\
\hline \multirow[t]{8}{*}{ Ch2 PCH06/104 } & $\mathrm{NO}$ & Bintje & ns & ns & neg & $\mathrm{nt}$ & nt \\
\hline & $\mathrm{NO}$ & Beate & ns & $\mathrm{m}$ & pos & $\mathrm{nt}$ & nt \\
\hline & $\mathrm{NO}$ & Juno & $\mathrm{nl}$ & ns & neg & $\mathrm{nt}$ & $\mathrm{nt}$ \\
\hline & DK & Hamlet & ns & ns & pos & neg & neg \\
\hline & DK & Mette & ns & ns & pos & neg & neg \\
\hline & PL & Jelly & ns & ns & pos & $\mathrm{nt}$ & pos \\
\hline & PL & Dali & ns & ns & pos & nt & pos \\
\hline & $\mathrm{NL}$ & Caesar & $\mathrm{nl}$ & lc & pos & $\mathrm{nt}$ & $\mathrm{nt}$ \\
\hline \multirow[t]{7}{*}{ US1-PRI } & $\mathrm{NO}$ & Bintje & ns & ns & neg & $\mathrm{nt}$ & nt \\
\hline & $\mathrm{NO}$ & Beate & ns & ns & pos & $\mathrm{nt}$ & $\mathrm{nt}$ \\
\hline & NO & Juno & ns & ns & neg & $\mathrm{nt}$ & $\mathrm{nt}$ \\
\hline & $\mathrm{DK}$ & Hamlet & ns & ns & pos & neg & neg \\
\hline & DK & Mette & ns & ns & pos & neg & neg \\
\hline & PL & Natascha & ns & ns & pos & $\mathrm{nt}$ & pos \\
\hline & $\mathrm{NL}$ & Caesar & $\mathrm{nl}$ & lc & pos & $\mathrm{nt}$ & $\mathrm{nt}$ \\
\hline
\end{tabular}




\section{Tomato (Solanum lycoperiscum)}

Six partners tested symptom development in $S$. lycopersicum with the reference cv. Moneymaker tested by all partners (Table 4). Differences in both local and systemic symptoms on this cultivar were observed between the geographical locations. It is remarkable that none of the three virus strains showed symptoms under Polish conditions even though the plants were infected as confirmed by ELISA. In Slovenia, local symptoms were present for all three virus strains. Under Danish growth conditions only US1 developed local symptoms while the same occurred for Ch2 in Hungary. In all trials, except for Norway where no ELISA test were done, the inoculated plants tested positive and where ELISA tests of roots and back inoculation were included, these tests were positive.

Differences in symptom development between the local cultivars were also recorded (Table 5). In most local cultivars no local symptoms developed, except in Slovenia where inoculated leaves of all infected tomato plants developed chlorotic and necrotic lesions. No symptoms developed under Polish conditions, except in 'Remiz' inoculated with $\mathrm{Ch} 2$ which showed mosaic, even though all the plants were infected. The same situation applied to 'Favorita' in Denmark inoculated with EU-tom. Like with the 'Moneymaker', differences between the three virus strains were also seen for the systemic symptoms. In all trials systemic leaves of inoculated plants tested positive in ELISA and where test of roots and back inoculation were included, these were also positive.

In conclusion, all three virus strains infect tomato systematically and in general only systemic symptoms develop (see Table 6). Differences in symptom development according to geographic location were recorded.

\section{Indicator plant species}

$N$. occidentalis 37B was tested in Hungary, Norway and Poland, and gave chlorotic local lesions when inoculated by EU-tom and US1, whereas the $\mathrm{Ch} 2$ gave necrotic local lesions. The EU-tom gave mild systemic mosaic, US1 more pronounced systemic mosaic, and Ch2 more necrotic and systemic mosaic. No important differences were seen between the localities. Symptoms are shown in Figs. 1 and 2.
Table 4 Symptom development in different European countries of three PepMV isolates in S. lycopersicum cv. Moneymaker and results of ELISA tests on leaves and roots of inoculated plants and on leaves of back inoculated plants
$D K$ Denmark, $H U$ Hungary, $N L$ The Netherlands, $N O$ Norway, $P L$ Poland, SI Slovenia

$n t$ not tested, $g r$ growth reduction, $l b$ leaf bubbling, $l c$ leaf chlorosis, $l d$ leaf deformation, $\ln$ leaf necrosis, $m$ mosaic, $n h$ nettle head, $n l$ necrotic lesion, $n s$ no symptoms, $v c$ vein clearing, ys yellow spots

\begin{tabular}{|c|c|c|c|c|c|c|}
\hline \multirow[t]{2}{*}{ PepMVisolate } & \multirow[t]{2}{*}{ Country } & \multicolumn{2}{|c|}{ Symptoms } & \multicolumn{2}{|c|}{ DAS ELISA pos/neg } & \multirow{2}{*}{$\begin{array}{l}\text { Back } \\
\text { inoculated } \\
\text { leaves }\end{array}$} \\
\hline & & local & systemic & leaves & roots & \\
\hline \multirow[t]{6}{*}{ EU-tom 1066} & DK & ns & $\mathrm{m}$ & pos & pos & nt \\
\hline & $\mathrm{HU}$ & ns & ld, ys, lc & pos & nt & $\mathrm{nt}$ \\
\hline & NL & ns & $\mathrm{lb}, \mathrm{m}, \mathrm{nh}$ & pos & $\mathrm{nt}$ & pos \\
\hline & $\mathrm{NO}$ & ns & $\mathrm{m}, \ln$ & $\mathrm{nt}$ & $\mathrm{nt}$ & $\mathrm{nt}$ \\
\hline & PL & ns & ns & pos & $\mathrm{nt}$ & pos \\
\hline & SI & lc, $\ln$ & $\mathrm{m}, \mathrm{lc}$ & pos & $\mathrm{nt}$ & pos \\
\hline \multirow[t]{6}{*}{ CH2 PCH06/104 } & DK & ns & $\mathrm{m}, \mathrm{vc}, \mathrm{gr}$ & pos & pos & pos \\
\hline & $\mathrm{HU}$ & lc, $\mathrm{nl}$ & lc, $\ln$ & pos & $\mathrm{nt}$ & $\mathrm{nt}$ \\
\hline & $\mathrm{NL}$ & ns & $\mathrm{lb}, \mathrm{m}, \mathrm{nh}, \mathrm{ys}, \mathrm{ld}$ & pos & $\mathrm{nt}$ & pos \\
\hline & $\mathrm{NO}$ & ns & $\mathrm{m}$ & $\mathrm{nt}$ & $\mathrm{nt}$ & $\mathrm{nt}$ \\
\hline & PL & ns & ns & pos & $\mathrm{nt}$ & pos \\
\hline & SI & lc, $\ln$ & $\mathrm{m}, \mathrm{nh}, \mathrm{lb}, \mathrm{lc}$ & pos & nt & pos \\
\hline \multirow[t]{6}{*}{ US1-PRI } & DK & ys & $\mathrm{lb}, \mathrm{m}, \mathrm{gr}$ & pos & pos & pos \\
\hline & $\mathrm{HU}$ & ns & ys, m, ld & pos & $\mathrm{nt}$ & nt \\
\hline & NL & ns & $\mathrm{lb}, \mathrm{m}, \mathrm{nh}, \mathrm{ys}$ & pos & $\mathrm{nt}$ & pos \\
\hline & $\mathrm{NO}$ & ns & $\mathrm{m}$ & $\mathrm{nt}$ & $\mathrm{nt}$ & nt \\
\hline & PL & ns & ns & pos & $\mathrm{nt}$ & pos \\
\hline & SI & lc, ln & lc, m, lb, nh, ys & pos & $\mathrm{nt}$ & pos \\
\hline
\end{tabular}


Table 5 Symptom development in different European countries of three PepMV isolates in local cvs of S. lycopersicum and results of ELISA tests on leaves and roots of inoculated plants and on

\begin{tabular}{|c|c|c|c|c|c|c|c|}
\hline \multirow[t]{2}{*}{ PepMV isolate } & \multirow[t]{2}{*}{ Country } & \multirow[t]{2}{*}{ Cultivar } & \multicolumn{2}{|c|}{ Symptoms } & \multicolumn{2}{|c|}{$\begin{array}{l}\text { DAS ELISA } \\
\text { pos/neg }\end{array}$} & \multirow{2}{*}{$\begin{array}{l}\text { Back } \\
\text { inoculated } \\
\text { leaves }\end{array}$} \\
\hline & & & local & systemic & leaves & roots & \\
\hline \multirow[t]{12}{*}{ EU-tom 1066} & $\mathrm{DK}$ & Cedrico & $\mathrm{ns}$ & $\mathrm{vc}, \mathrm{lc}$ & pos & pos & $\mathrm{nt}$ \\
\hline & $\mathrm{DK}$ & Flavorino & $\mathrm{vc}$ & $\mathrm{vc}, \mathrm{lc}$ & pos & pos & $\mathrm{nt}$ \\
\hline & DK & Favorita & ns & ns & pos & pos & $\mathrm{nt}$ \\
\hline & $\mathrm{HU}$ & Profilo & $\mathrm{ns}$ & ys & pos & $\mathrm{nt}$ & $\mathrm{nt}$ \\
\hline & $\mathrm{HU}$ & Vulcanos F1 & $\mathrm{ns}$ & ld, ys & pos & $\mathrm{nt}$ & $\mathrm{nt}$ \\
\hline & $\mathrm{NL}$ & Capricia & ns & $\mathrm{m}, \mathrm{ys}, \mathrm{ns}$ & pos & nt & pos \\
\hline & $\mathrm{NL}$ & Elanto & $\mathrm{ns}$ & $\mathrm{lb}, \mathrm{m}, \mathrm{nh}$ & pos & $\mathrm{nt}$ & pos \\
\hline & PL & Beat Lux & $\mathrm{ns}$ & ns & pos & $\mathrm{nt}$ & pos \\
\hline & PL & Krakus & $\mathrm{ns}$ & $\mathrm{ns}$ & pos & $\mathrm{nt}$ & pos \\
\hline & PL & Remiz & $\mathrm{ns}$ & ns & pos & nt & pos \\
\hline & SI & Rio Grande & lc, $\ln$ & $\mathrm{m}, \mathrm{lb}, \mathrm{ys}, \mathrm{lc}$ & pos & nt & $\mathrm{nt}$ \\
\hline & SI & Roma & lc, $\ln$ & lc, $\ln , \mathrm{lb}$ & pos & nt & $\mathrm{nt}$ \\
\hline \multirow[t]{12}{*}{ Ch2 PCH06/104 } & DK & Cedrico & ns & lc, nh & pos & pos & pos \\
\hline & DK & Flavorino & $\mathrm{ns}$ & lc, nh & pos & pos & pos \\
\hline & DK & Favorita & $\mathrm{ns}$ & leaf roll & pos & pos & pos \\
\hline & $\mathrm{HU}$ & Profilo & ns & ld, ys & pos & $\mathrm{nt}$ & nt \\
\hline & $\mathrm{HU}$ & Vulcanos F1 & $\mathrm{ns}$ & $\mathrm{ys}, \mathrm{m}, \ln$ & pos & $\mathrm{nt}$ & nt \\
\hline & NL & Capricia & $\mathrm{ns}$ & $\mathrm{lb}, \mathrm{m}, \mathrm{nh}, \mathrm{ys}$ & pos & $\mathrm{nt}$ & pos \\
\hline & NL & Elanto & ns & lb, ld, m, nh, ys & pos & nt & pos \\
\hline & PL & Beat Lux & $\mathrm{ns}$ & ns & pos & $\mathrm{nt}$ & pos \\
\hline & PL & Krakus & ns & ns & pos & nt & pos \\
\hline & PL & Remiz & $\mathrm{ns}$ & $\mathrm{m}$ & pos & $\mathrm{nt}$ & pos \\
\hline & SI & Rio Grande & lc, $\ln$ & $\mathrm{lc}, \mathrm{m}, \mathrm{lb}$ & pos & nt & nt \\
\hline & SI & Roma & lc, $\ln$ & $\mathrm{lc}, \mathrm{m}, \mathrm{ln}, \mathrm{lb}, \mathrm{nh}$ & pos & $\mathrm{nt}$ & $\mathrm{nt}$ \\
\hline \multirow[t]{12}{*}{ US1-PRI } & $\mathrm{DK}$ & Cedrico & ns & lc & pos & pos & pos \\
\hline & DK & Flavorino & $\mathrm{ns}$ & lc, ys & pos & pos & pos \\
\hline & $\mathrm{DK}$ & Favorita & $\mathrm{ns}$ & lc, leaf roll & pos & pos & pos \\
\hline & $\mathrm{HU}$ & Profilo & $\mathrm{ns}$ & $\mathrm{m}, \mathrm{ys}, \mathrm{ld}$ & pos & nt & nt \\
\hline & $\mathrm{HU}$ & Vulcanos F1 & $\mathrm{ns}$ & $\mathrm{m}, \mathrm{ys}$ & pos & $\mathrm{nt}$ & $\mathrm{nt}$ \\
\hline & NL & Capricia & ns & $\mathrm{lb}, \mathrm{m}, \mathrm{nh}, \mathrm{ys}$ & pos & nt & pos \\
\hline & NL & Elanto & $\mathrm{ns}$ & $\mathrm{lb}, \mathrm{m}, \mathrm{nh}, \mathrm{ys}$ & pos & nt & pos \\
\hline & PL & Beat Lux & $\mathrm{ns}$ & ns & pos & $\mathrm{nt}$ & pos \\
\hline & PL & Krakus & ns & ns & pos & $\mathrm{nt}$ & pos \\
\hline & PL & Remiz & $\mathrm{ns}$ & ns & pos & $\mathrm{nt}$ & pos \\
\hline & SI & Rio Grande & lc, $\ln$ & $\mathrm{lc}, \mathrm{m}, \mathrm{lb}, \mathrm{nh}, \mathrm{ys}$ & pos & $\mathrm{nt}$ & nt \\
\hline & SI & Roma & lc, $\ln$ & $\mathrm{lc}, \mathrm{m}, \mathrm{lb}, \mathrm{ln}$ & pos & $\mathrm{nt}$ & $\mathrm{nt}$ \\
\hline
\end{tabular}

$n t$ not tested, $l b$ leaf bubbling, $l c$ leaf chlorosis, $l d$ leaf deformation, $l n$ leaf necrosis, $m$ mosaic, $n h$ nettle head, $n l$ necrotic lesion, $n s$ no symptoms, $v b$ vein banding, $v c$ vein clearing, $v n$ veinal necrosis, $y s$ yellow spots leaves of back inoculated plants $D K$ Denmark, $H U$ Hungary, $N L$ The Netherlands, $P L$ Poland, SI Slovenia 
Table 6 Summary of the total results over all countries of infection rates of three PepMV isolates in five crops, as determined by ELISA, and development of systemic symptoms. The results for each crop are divided into the common reference cultivar and the total of the local cultivar or species

\begin{tabular}{|c|c|c|c|c|c|c|c|}
\hline \multicolumn{2}{|c|}{ PepMV isolates } & \multicolumn{2}{|c|}{ EU-tom 1066} & \multicolumn{2}{|c|}{ Ch2 PCH 06/104 } & \multicolumn{2}{|l|}{ US1-PRI } \\
\hline Crop & Cultivar/ species & Syst inf* & Syst sympt** & Syst inf & Syst sympt & Syst inf & Syst sympt \\
\hline \multirow[t]{2}{*}{ Tomato } & Money Maker ${ }^{\mathrm{a}}$ & $5 / 5$ & $5 / 6$ & $5 / 5$ & $5 / 6$ & $5 / 5$ & $5 / 6$ \\
\hline & Other cvs ${ }^{\mathrm{b}}$ & $12 / 12$ & $8 / 12$ & $12 / 12$ & $10 / 12$ & $12 / 12$ & $9 / 12$ \\
\hline \multirow[t]{2}{*}{ Eggplant } & Black Beauty $^{\mathrm{a}}$ & $5 / 5$ & $2 / 5$ & $5 / 5$ & $4 / 5$ & $5 / 5$ & $1 / 5$ \\
\hline & Other cvs ${ }^{b}$ & $10 / 10$ & $5 / 10$ & $10 / 10$ & $8 / 10$ & $7 / 10$ & $6 / 10$ \\
\hline \multirow[t]{2}{*}{ Potato } & Bintje $^{a}$ & $1 / 3$ & $0 / 3$ & $1 / 3$ & $0 / 3$ & $1 / 3$ & $0 / 3$ \\
\hline & Other cvs ${ }^{\mathrm{b}}$ & $8 / 16$ & $0 / 16$ & $6 / 16$ & $1 / 16$ & $5 / 16$ & $0 / 16$ \\
\hline \multirow[t]{2}{*}{ Pepper } & Bell Boy ${ }^{\mathrm{a}}$ & $1 / 5$ & $0 / 5$ & $1 / 5$ & $0 / 5$ & $2 / 5$ & $1 / 5$ \\
\hline & Other cvs ${ }^{b}$ & $3 / 15$ & $0 / 15$ & $2 / 15$ & $0 / 15$ & $3 / 15$ & $1 / 15$ \\
\hline \multirow[t]{2}{*}{ Tobacco } & N. occidentalis ${ }^{\mathrm{a}}$ & $3 / 3$ & $3 / 3$ & $3 / 3$ & $3 / 3$ & $3 / 3$ & $3 / 3$ \\
\hline & Other species ${ }^{\mathrm{b}}$ & $7 / 7$ & $7 / 7$ & $5 / 7$ & $4 / 7$ & $7 / 7$ & $7 / 7$ \\
\hline
\end{tabular}

* Syst inf systemic infection determined by ELISA, ** Syst sympt systemic symptoms

${ }^{\text {a }}$ number of locations at which positive results were noted/ number of locations conducting test

b number of cultivars or species showing positive results / total number tested, across all locations

$N$. rustica was only tested by the Norwegian partner. All three isolates produced local lesions. The EU-tom and US1 gave chlorotic local lesions and $\mathrm{CH} 2$ produced weak local lesions. The systemic symptoms produced by EU-tom consisted of mild mosaic, whereas US1 gave a more pronounced vein yellowing. Ch2 gave no symptoms in newly developed leaves and absence of virus was confirmed by ELISA. The systemic symptoms are shown in Fig. 3.
$N$. glutinosa was only tested by the Norwegian partner. The strains EU-tom and US1 gave local chlorotic lesions and systemic yellow vein banding, while Ch2 gave no infection at all. These results were confirmed by ELISA.

N. tabacum cv. Xanthi was tested at three locations: Bulgaria, Denmark and Poland. The inoculated leaves showed chlorotic lesions, sometimes developing into necrotic lesions, whereas the systemic symptoms varied
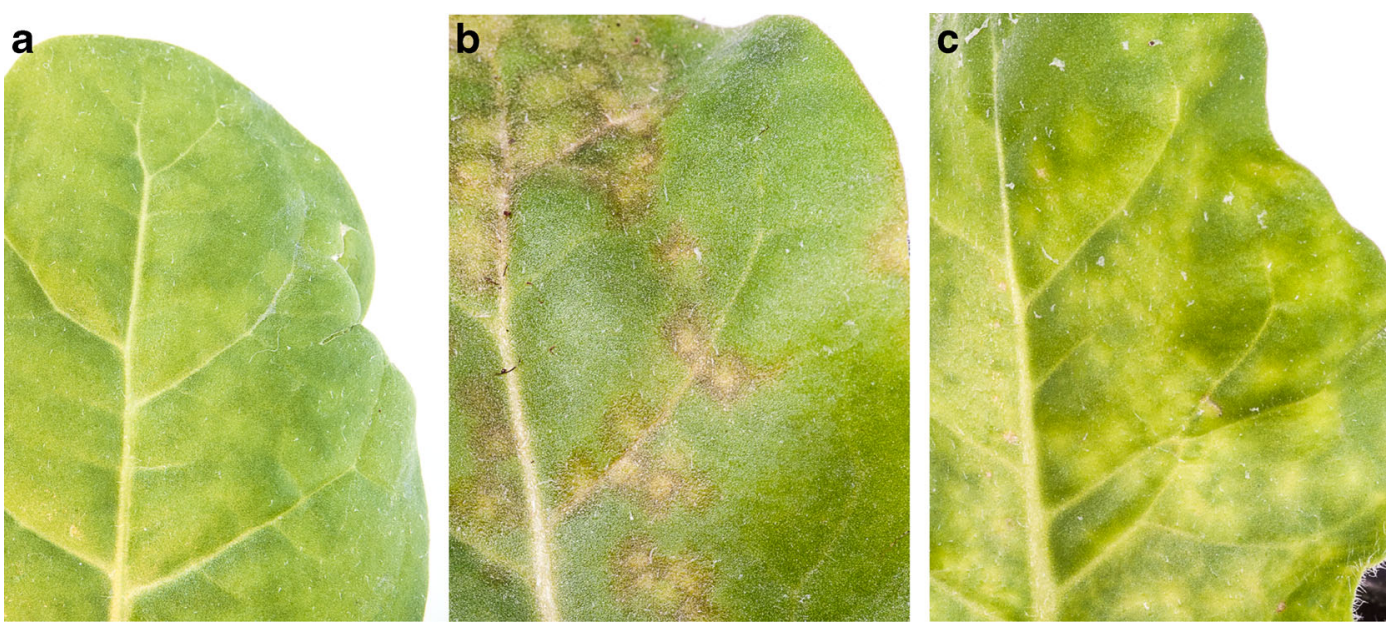

Fig. 1 Local symptoms produced by PepMV strain a EU-tom isolate 1066, b Ch2 isolate PCH06/104, an c and US1 isolate PRI, in $N$. occidentalis $37 \mathrm{~B} 5$ days post inoculation 

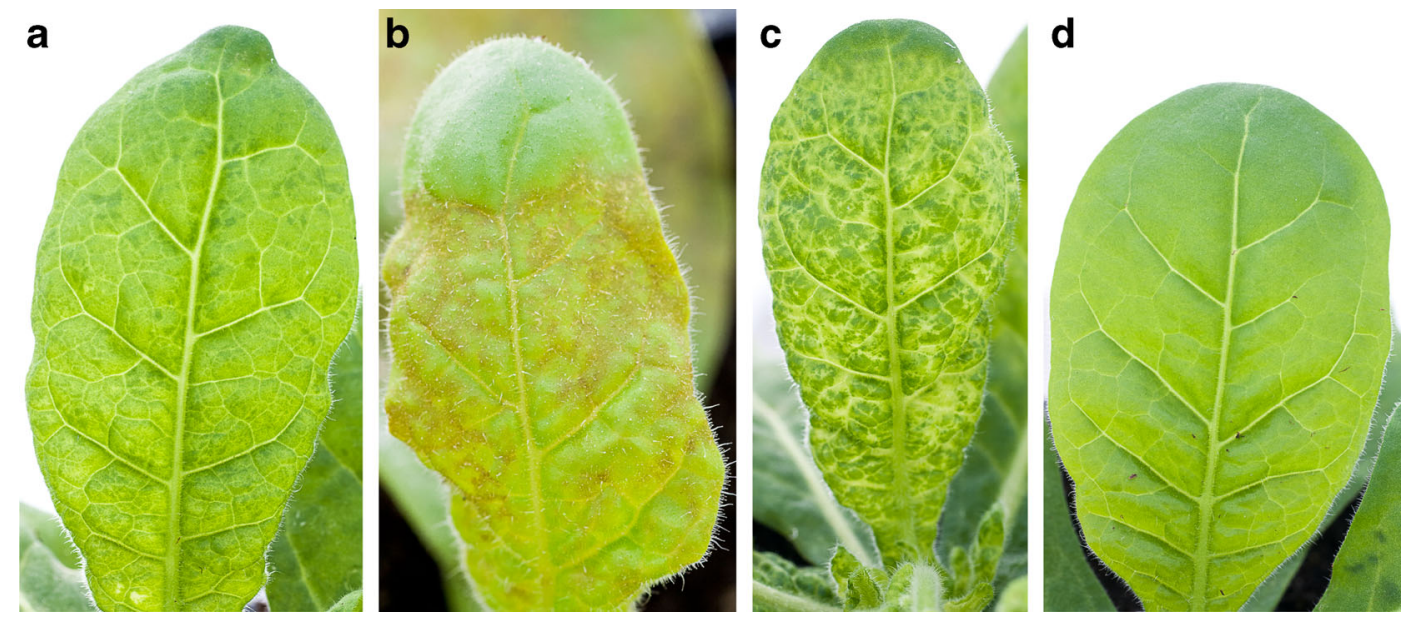

Fig. 2 Systemic symptoms of PepMV a EU-tom isolate 1066, b Ch2 isolate PCH06/104, and c US1 isolate PRI in N. occidentalis 37B, 7 days post inoculation. Healthy control to the right $\mathbf{d}$

between the locations with mosaic in Poland and chlorotic and necrotic lesions in Bulgaria and Denmark.

$N$. benthamiana was tested at two locations, Poland and Norway, and no influence of location was seen. All three virus strains developed local chlorotic lesions. Local lesions were seen as soon as 3-4 days after inoculation, and systemic symptoms consisting of mosaic and growth reduction started to develop as early as 4-5 days after inoculation for all three strains.

C. quinoa was studied by the Norwegian partner. The strains EU-tom and US1 did not give any visible symptoms in C. quinoa. The ELISA test of the inoculated leaves showed no presence of EU-tom, but did confirm the presence of US1 in inoculated leaves in one out of five plants. The strain $\mathrm{Ch} 2$ gave chlorotic local lesions and systemic mosaic in all the five plants tested, and presence of PepMV in the plants was confirmed by ELISA.

\section{Discussion}

Virus inoculation experiments with test plants will always depend on several variables: the virus strain, the genetic variant of the test plant, individual variation between plants and environmental conditions such as the amount of light, temperature and also time of the year. We tried to minimize the variation caused by different isolates by distributing well characterized isolates of three selected strains of PepMV to all partners involved. Also seeds of the test plant N. occidental $37 \mathrm{~B}$ were distributed to all partners from one source (Plant
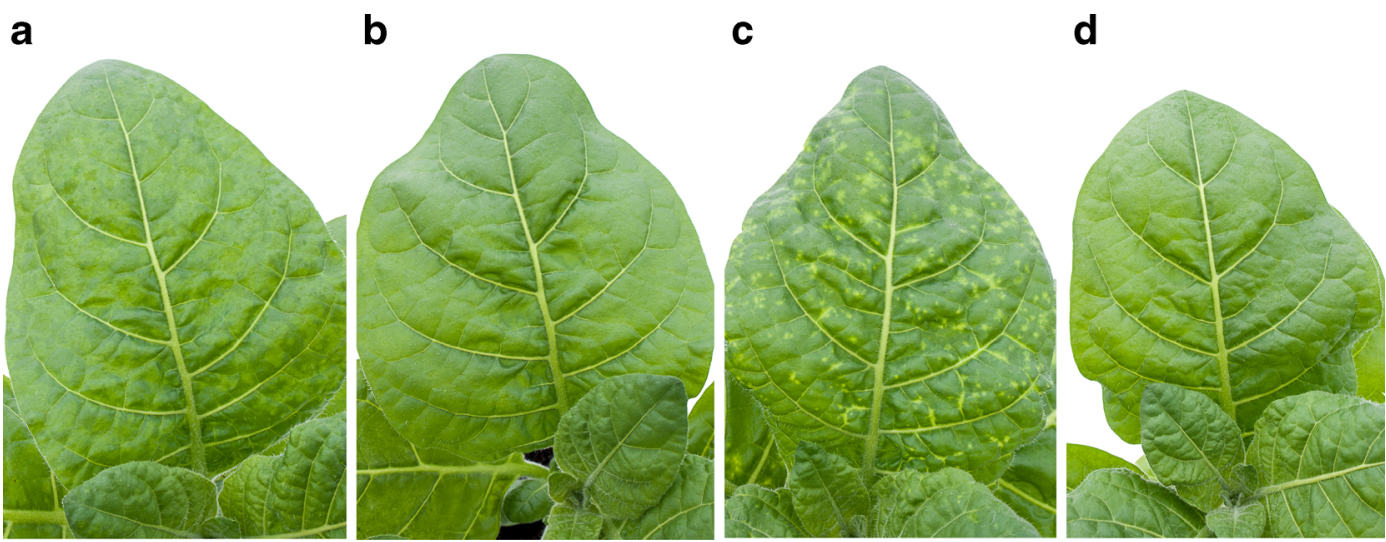

Fig. 3 Systemic symptoms of PepMV strains (a) EU-tom isolate 1066 and (c) US1 isolate PRI in N. rustica 16 days post inoculation. Ch2 gave no infection (b). Healthy control to the right (d) 
Research International, Wageningen, the Netherlands) and for all plant species tested one common cultivar was included by the partners. Most of the test plant studies were performed in spring, summer and autumn, avoiding the winter period. All inoculations were done with five parallel plants from each species/cultivar. These factors helped to minimize variation.

\section{Eggplant (S. melongena)}

S. melongena is clearly a systemic host for all three PepMV types, as can be seen from the positive ELISA results in both leaves and roots and positive back inoculation results. This shows that $S$. melongena has the potential to serve as an alternative host to tomato, as also stated by Gómez et al. (2009), who noticed that eggplant could serve as reservoir in the fields, since the eggplant cropping season in South East of Spain is long enough to bridge between tomato cropping seasons. All three PepMV strains very seldom evoke local symptoms and only sometimes systemic leaf symptoms. The results with the reference cv. Black Beauty show that symptom development is dependent on both locality and virus type. Variation in symptom development was also reported by Papayiannis et al. (2012), who found no symptoms in Cyprus with EU-tom and $\mathrm{Ch} 2$ group isolates; by Salomone and Roggero (2002) reporting local and systemic symptoms in Italy with an EU-tom group isolate; by van der Vlugt et al. (2002) finding no local, but systemic symptoms by an EU-tom group isolate in the Netherlands; and by Pospieszny et al. (2008) finding systemic symptoms in Poland by an EU-tom and Ch2 group isolate.

\section{Sweet pepper (C. annuum)}

The most interesting results with $C$. annuum are that US1 induced systemic necrotic lesions in all three local cultivars tested in Bulgaria. Van der Vlugt et al. (2002), Verhoeven et al. (2003), Pospieszny et al. (2008), Gómez et al. (2009) and Papayiannis et al. (2012) did not find any infection after inoculation with one or more of the virus strains used in this study. Only HasiówJaroszewska et al. (2010a) and Fakhro et al. (2011) recorded a systemic PepMV infection in C. annuиm without and with symptoms, respectively, after inoculation with EU-tom genotype isolates.

We conclude that $C$. annuum is in general not a systemic host for the three virus isolates used in this study, and it is most likely that $C$. annuum does not represent an important host in the epidemiology of PepMV.

\section{Potato (S. tuberosum)}

Our results show that potato can be infected by the most common strains of PepMV occurring in Europe, although local and systemic symptoms seldom develop. This is in contrast to the results reported earlier by Salomone and Roggero (2002), Van der Vlugt et al. (2002), Pospieszny et al. (2008), Hasiów-Jaroszewska et al. (2010b) and Papayiannis et al. (2012), who found no infection in inoculated potato cultivars. However, the Norwegian results from cv. Beate inoculated with the isolate TomA2001-1 (a Ch2 genotype isolate, Van der Vlugt unpublished) showed that a systemic infection can occur in combination with a sensitive cultivar and that the virus can be transmitted through the tubers. Jones et al. (1980) also recorded symptomless infection in four potato cultivars, Martin and Mousserion (2002) recorded infection and symptom development in four out of seven inoculated potato cultivars, and Fakhro et al. (2011) recorded symptomless infection with an EU-tom strain isolate in a single cultivar.

\section{Tomato (S. lycoperiscum)}

Completely in line with many different observations tomato was readily infected with all three strains (for example Verhoeven et al. 2003; Hanssen et al. 2008; van der Vlugt 2009). The three strains did not give severe symptoms in our experiments but varied in symptom development. There appears to be no correlation between symptom severity in tomato and virus strain. Geographic location was found to influence symptom development which is most likely because of different growth conditions.

Indicator plants

Jones et al. (1980), Martin and Mousserion (2002), Van der Vlugt et al. (2002), Verhoeven et al. (2003) and Gómez et al. (2009) found $N$. occidentalis to be readily infected by PepMV and showing symptoms.

The results from the present study with $N$. occidentalis 37B confirm its susceptibility and the usefulness of this test plant to differentiate the virus strains. The three strains gave different symptoms and 
especially the $\mathrm{Ch} 2$ type isolate $\mathrm{PCH} 06 / 104$ showed easily recognizable symptoms of necrotic local lesions.

The systemic symptoms in $N$. rustica also proved useful for differentiating the strains. However, varying symptoms have been described in the literature. Martin and Mousserion (2002) recorded no infection; Gómez et al. (2009) found only local latent infection, while van der Vlugt et al. (2002) and Fakhro et al. (2011) recorded visible symptoms.

$N$. glutinosa was described as the best propagation and assay host for PepMV by Jones et al. (1980), while Verhoeven et al. (2003) when investigating 15 tomato isolates of PepMV, obtained a varying score of infection in N. glutinosa that differed between isolates. We found that this test plant could differentiate $\mathrm{Ch} 2$ from the other two strains, but not between EU-tom and US1 as they induced identical symptoms.

$N$. benthamiana does not differentiate the three isolates as clearly as $N$. occidentlais $37 \mathrm{~B}$ and $N$. rustica, but may be a useful propagation host. Fakhro et al. (2011) recorded clear symptoms and the highest virus concentration in $N$. benthamiana when comparing seven Nicotiana species. Other papers also report systemic symptoms in N. benthamiana (Martin and Mousserion 2002; Salomone and Roggero 2002; Van der Vlugt et al. 2002; Pospieszny et al. 2008; Gómez et al. 2009; Hasiów-Jaroszewska et al. 2010a).

N. tabacum cv. Xanthi was clearly infected by all three isolates. Infection was also reported by HasiówJaroszewska et al. (2010a) for three out of five isolates tested, two from the EU-tom strain and one from the $\mathrm{CH} 2$ strain. However, Martin and Mousserion (2002), Verhoeven et al. (2003) and Gómez et al. (2009) did not obtain infection in N. tabacum cv. Xanthi in their trials.

The varying results obtained in $C$. quinoa are very much in line with results from other investigations. C. quinoa did not produce visible symptoms when inoculated with the original PepMV isolate (Jones et al. 1980). Verhoeven et al. (2003) and Fakhro et al. (2011) found no infection in C. quinoa with EU-tom and E397 (EU strain) isolates respectively, whereas Martin and Mousserion (2002) reported a latent infection in C. quinoa with an isolate from tomato in France, probably belonging to the EU-tom strain. Salomone and Roggero (2002) working with a tomato isolate from Sardinia (PepMV-To) and Pospieszny et al. (2008) working with the isolate PepMV-SW (EU-tom strain) reported chlorotic local lesions in this host.
In general, varying results with respect to infection and symptom development have been obtained with the included indicator plant species. Only $N$. glutinosa and $N$. benthamiana developed at least systemic symptoms in all the references cited. $N$. occidentalis 37B appears to be the most useful indicator to differentiate between the three strains of PepMV included in the present investigation.

In a recent paper Moreno-Pérez et al. (2014) concluded from a study on PepMV in wild Solanum species in Peru that host adaptation of PepMV isolates likely played in role in the infections in domesticated tomatoes as observed since 1999. They conclude that the most probable ancestral sequence of PepMV came from a wild Solanum species and that a high incidence of PepMV in wild tomato relatives would favour virus spread to crops and its efficient multiplication in different Solanum species, including tomato, allowing its establishment as an epidemic pathogen. The three PepMV used in this study could all be regarded as typical tomato strains because they were all isolated from tomato or tomato seeds. These strains indeed show a good capacity to infect tomato but can also infect other solanaceous hosts, like eggplant, potato and tobacco, as can be deduced from the ELISA results of the inoculated plants (Table 6). However, in general they show significantly less clear symptoms in these plants (except tobacco). This could point to a specific adaptation of these strains to solanaceous species other than their alleged original wild S. lycopersicon hosts (Moreno-Pérez et al. 2014). It remains to be tested if this adaptation indeed went to the expense of their ability to infect wild S. lycopersicon hosts. In this respect it should also be noted that strain US1 (which was not included in the study of Moreno-Perez), and initially found on tomato seeds imported from Chile, is generally very capable of infecting eggplant and at the same time is rarely found in tomato. This could possibly also indicate that this strain is not yet adapted to tomato. It could be speculated that this US1 strain could have originated from another wild solanaceous host, different from tomato.

With respect to practical application our results indicate that PepMV strains, adapted to tomato, clearly show the potential to expand their host range to other solanaceous crops like eggplant and potato. An example of this is the infection of potato cv. Beate with PepMV TomA2001-1 which not only resulted in systemic symptoms in all inoculated plants, but also in secondary infections of plants grown from harvested tubers. This 
is an indication that the adaptation of PepMV strains to other host plants is likely to be a continuing process.

Our study on host range and symptomatology of PepMV comprised three well characterized strains, several important solanaceous crops and several test plants at ten different locations in Europe. This gives a more comprehensive study on this topic than published before. Given the world wide spread of PepMV and in some countries, solid establishment in tomato crops, and the observed high genetic variability between isolates, the switch of any of these 'tomato' isolates to another agriculturally important solanaceous crop like potato, pepper or eggplant is likely to be more than just a hypothetical possibility.

Acknowledgments This work was performed under the frame of EU Framework Programme 6 project: "Pepino mosaic virus. Epidemiology, economic impact and pest risk analysis" (PEPEIRA).

Open Access This article is distributed under the terms of the Creative Commons Attribution 4.0 International License (http:// creativecommons.org/licenses/by/4.0/), which permits unrestricted use, distribution, and reproduction in any medium, provided you give appropriate credit to the original author(s) and the source, provide a link to the Creative Commons license, and indicate if changes were made.

\section{References}

Alfaro-Fernández, A., Córdoba-Sellés, M. C., Herrera-Vásquez, J. A., Cebrián, M. C., \& Jordá, C. (2009). Transmission of Pepino mosaic virus by the fungal vector Olpidium virulentus. Journal of Phytopathology, 158, 217-226.

Charmichael, D. J., Rey, M. E. C., Naidoo, S., Cook, G., \& van Heerden, S. W. (2011). First report of Pepino mosaic virus infecting tomato in South Africa. Plant Disease, 95(6), 767.2.

Córdoba, M. C., Martínez-Priego, L., \& Jordá, C. (2004). New natural hosts of Pepino mosaic virus in Spain. Plant Disease, $88,906$.

Córdoba-Sellés, M. C., García-Rández, A., Alfaro-Fernández, A., \& Jordá-Gutiérrez, C. (2007). Seed transmission of pepino mosaic virus and efficacy of tomato seed disinfection treatments. Plant Disease, 91, 1250-1254.

Efthimiou, K. E., Gatsios, A. P., Aretakis, K. C., Papayannis, L. C., $\&$ Katis, N. I. (2011). First report of Pepino mosaic virus infecting greenhouse cherry tomato in Greece. Plant Disease, 95(1), 78.2.

Fakhro, A., von Bargen, S., Bandte, M., Büttner, C., Franken, P., \& Schwarz, D. (2011). Susceptibility of different plant species and tomato cultivars to two isolates of Pepino mosaic virus. European Journal of Plant Pathology, 129, 579-590.

Gómez, P., Sempere, R. N., Elena, S. F., \& Aranda, M. A. (2009). Mixed infections of Pepino mosaic virus strains modulate the evolutionary dynamics of this emergent virus. Journal of Virology, 83, 12378-12387.

Hanssen, I. M., Paeleman, A., Wittemans, L., Goen, K., Lievens, B., Bragard, C., Vanachter, A. C. R. C., \& Thomma, B. P. H. J. (2008). Genetic characterization of Pepino mosaic virus isolates from Belgian greenhouse tomatoes reveals genetic recombination. European Journal of Plant Pathology, 121, 131-146.

Hanssen, I. M., Paeleman, A., Vandewoestijne, E., Van Bergen, L., Bragard, C., Lievens, B., Vanachter, A. C. R. C., \& Thomma, B. P. H. J. (2009). Pepino mosaic virus isolates and differential symptomatology in tomato. Plant Pathology, 58, 450 460.

Hanssen, I. M., Mumford, R., Blystad, D.-G., Cortez, I., HasiówJaroszewska, B., Hristova, D., Pagán, I., Pereira, A.-M., Peters, J., Pospieszny, H., Ravnikar, M., Stijger, I., Tomassoli, L., Varveri, C., van der Vlugt, R., \& Nielsen, S. L. (2010). Seed transmission of Pepino mosaic virus in tomato. European Journal of Plant Pathology, 126, 145-152.

Hasiów-Jaroszewska, B., Borodynko, N., Jackowiak, P., Figlerowicz, M., \& Pospieszny, H. (2010a). Pepino mosaic virus - a pathogen of tomato crops in Poland: biology, evolution and diagnostics. Journal of Plant Protection Research, 50, 470-476.

Hasiów-Jaroszewska, B., Jackowiak, P., Borodynko, N., Figlerowicz, M., \& Pospieszny, H. (2010b). Quasispecies nature of Pepino mosaic virus and its evolutionary dynamics. Virus Genes, 41, 260-267.

Jeffries, C. J. (1998). FAO/IPGRI technical guidelines for the safe movement of germplasm no. 19. Potato. Food and agriculture organization of the United Nations, Rome/International Plant Genetic Resources Institute, Rome pp 177

Jones, R. A. C., Koenig, R., \& Lesemann, D. E. (1980). Pepino mosaic virus, a new potexvirus from pepino (Solanum muricatum). Annals of Applied Biology, 94, 61-68.

Jordá, C., Lázaro Pérez, A., \& Martínez Culebras, P. (2001). First report of Pepino mosaic virus on natural hosts. Plant Disease, 85, 1292.

King, A. M. Q., Adams, M. J., Carstens, E. B., Lefkowitz, E. J., (eds). (2012). potexvirus, pp 912-915, in virus taxonomy, classification and nomenclature of viruses; ninth report of the international committee on taxonomy of viruses ( $\mathrm{p} 1327$ ) London, UK: Elsevier Academic Press

Ling, K.-S., \& Zhang, W. (2011). First report of Pepino mosaic virus infecting tomato in Mexico. Plant Disease, 95(8), 1035.

Martin, J., \& Mousserion, C. (2002). Potato varieties which are sensitive to the tomato strains of Pepino mosaic virus (PepMV). Phytoma Défence Végétaux, 552, 26-28.

Mehle, N., Gutierrez-Aguirre, I., Prezelj, N., Delić, D., Vidic, U., \& Ravnikar, M. (2014). Survival and transmission of potato virus Y, pepino mosaic virus, and potato spindle tuber viroid in water. Applied and Environmental Microbiology, 80(4), $1455-1462$.

Moreno-Pérez, M. G., Pagán, I., Aragón-Caballero, L., Cáceres, F., Aurora Fraile, A., \& García-Arenal, F. (2014). Ecological and genetic determinants of Pepino mosaic virus emergence. Journal of Virology, 88(6), 3359-3368.

Noël, P., Hance, T., \& Bragard, C. (2014). Transmission of the pepino mosaic virus by whitefly. European Journal of Plant Pathology, 138, 23-27. 
Pagan, I., Cordoba-Selles, M. D., Martinez-Priego, L., Fraile, A., Malpica, J. M., Jorda, C., \& Garcia-Arenal, F. (2006). Genetic structure of the population of pepino mosaic virus infecting tomato crops in Spain. Phytopathology, 96, 274-279.

Papayiannis, L. C., Kokkinos, C. D., \& Alfaro-Fernández, A. (2012). Detection, characterization and host range studies of Pepino mosaic virus in Cyprus. European Journal of Plant Pathology, 132, 1-7.

Pospieszny, H., Haslow, B., \& Borodynko, N. (2008). Characterization of two Polish isolates of Pepino mosaic virus. European Journal of Plant Pathology, 122, 443-445.

Salomone, A., \& Roggero, P. (2002). Host range, seed transmission and detection by ELISA and lateral flow of an Italian isolate of Pepino mosaic virus. Journal of Plant Pathology, 84, 65-68.

Samson, R. G., Allen, T. C., \& Whitworth, J. L. (1993). Evaluation of direct tissue blotting to detect potato viruses. American Potato Journal, 70, 257-265.

Schwarz, D., Beuch, U., Bandte, M., Fakhro, A., Büttner, C., \& Obermeier, C. (2010). Spread and interaction of pepino mosaic virus (PepMV) and pythium aphanidermatum in a closed nutrient solution recirculation system: effects on tomato growth and yield. Plant Pathology, 59(3), 443-452.

Shipp, J. L., Buitenhuis, R., Stobbs, L., Wang, K., Kim, W. S., \& Ferguson, G. (2008). Vectoring of pepino mosaic virus by bumble-bees in tomato greenhouses. Annals of Applied Biology, 153, 149-155.

Van der Vlugt, R. A. A. (2009). Pepino mosaic virus (review). Hellenic Plant Protection Journal, 2, 47-56.
Van der Vlugt, R. A. A., \& Stijger, C. C. M. M. (2008). Pepino mosaic virus. In B. W. J. Mahy \& M. H. V. Van Regenmortel (Eds.), Encyclopedia of virology (5th ed., pp. 103-108). Wageningen: Oxford Elsevier.

Van der Vlugt, R. A. A., Stijger, C. C. M. M., Verhoeven, J. T. J., \& Lesemann, D.-E. (2000). First report of Pepino mosaic virus on tomato. Plant Disease, 84, 103.

Van der Vlugt, R. A. A., Cuperus, C., Vink, J., Stijger, I. C. M. M., Lesemann, D.-E., Verhoeven, J. T. J., \& Roenhorst, J. W. (2002). Identification and characterization of Pepino mosaic potexvirus in tomato. Bulletin EPPO/EPPO Bulletin, 32, 503-508.

Verchot-Lubicz, J., Chang-Ming, Y., \& Bamunusinghe, D. (2007). Molecular biology of potexviruses: recent advances. Journal of General Virology, 88(6), 1643-1655.

Verhoeven, J. T. H. J., van der Vlugt, R., \& Roenhorst, J. W. (2003). High similarity between tomato isolates of pepino mosaic virus suggests a common origin. European Journal of Plant Pathology, 109, 419-425.

Werkman, A.W., \& Sansford, C.E. (2010). Pest risk analysis for pepino mosaic virus for the EU. Deliverable Report 4.3. EU Sixth Framework project PEPEIRA. http://www.pepeira. com.

Wright, D., \& Mumford, R. (1999). Pepino mosaic potexvirus (PepMV): first records in tomato in the United Kingdom. Plant disease notice (89th ed.). York, UK: Central Science Laboratory. 